\title{
Chemical pleurodesis for the management of refractory hepatic hydrothorax in patients with decompensated liver cirrhosis
}

\author{
Woo Jin Lee, Hong Joo Kim, Jung Ho Park, Dong II Park, Yong Kyun Cho, Chong II Sohn, \\ Woo Kyu Jeon, and Byung Ik Kim
}

\author{
Department of Internal Medicine, Kangbuk Samsung Hospital, Sungkyunkwan University School of Medicine, \\ Seoul, Korea
}

\begin{abstract}
Background/Aims: Hepatic hydrothorax in patients with decompensated liver cirrhosis is a challenging problem. Treatment with diuretics and intermittent thoracentesis can be effective in selected patients. However, there are few effective therapeutic options in patients who are intolerant of these therapies. This study investigated the clinical usefulness of chemical pleurodesis with or without video-assisted thoracoscopic surgery (VATS) for patients with refractory hepatic hydrothorax. Methods: Eleven consecutive patients with refractory hepatic hydrothorax who underwent chemical pleurodesis with or without VATS between July 2007 and February 2011 were enrolled in this study. The medical records and radiologic imagings of these patients were thoroughly reviewed. Results: The median number of chemical pleurodesis sessions performed was 3 (range: $2-10$ ). Successful pleurodesis was achieved in 8 of the 11 patients $(72.7 \%)$, $5(62.5 \%)$ of whom remained asymptomatic and hydrothorax free for a median follow-up of 16 weeks (range: 2-52 weeks). Complications were low-grade fever/leukocytosis $(n=11,100 \%)$, pneumonia $(n=1,9.1 \%)$, pneumothorax $(n=4,36.4 \%)$, azotemia/acute renal failure $(n=6,54.6 \%)$, and hepatic encephalopathy $(n=4,36.4 \%)$. Five patients were suspected as having procedure-related mortality $(45.5 \%)$ due to the occurrence of acute renal failure with hepatic failure. The overall survival was significantly longer in the success group than in the non-success group. Conclusions: Although chemical pleurodesis may improve the clinical symptoms and the radiologic findings in as many as $72.7 \%$ of patients with refractory hepatic hydrothorax, a significantly high prevalence of procedure-related morbidity and mortality hinders the routine application of this procedure for such patients. (Korean J Hepatol 2011;17:292-298)
\end{abstract}

Keywords: Hydrothorax; Chemical pleurodesis; Video-assisted thoracoscopic surgery; Liver cirrhosis

\section{INTRODUCTION}

Hepatic hydrothorax is defined as a significant pleural effusion, usually greater than $500 \mathrm{~mL}$, in a patient with liver cirrhosis but no primary cardiac or pulmonary diseases. ${ }^{1,2}$ In patients with hepatic hydrothorax, even a modest volume of pleural fluid can cause respiratory symptoms, in contrast to ascites, where a large volume can be well tolerated.

Hepatic hydrothorax is a relatively uncommon complication of end-stage liver with an estimated prevalence of $5-10 \%$ among cirrhotic patients. ${ }^{1-4}$ In spite of the numerous case reports describing clinical features and treatments for hepatic hydrothorax the current knowledge of this complication of cirrhosis is limited. Unfortunately the pathogenesis and therapy of hepatic hydrothorax have not been appropriately studied, therefore, proper guidelines on therapy based on good evidence have been difficult to establish.

The aim of current study is to examine the treatment outcomes of the 11 patients with refractory hepatic hydrothorax who underwent chemical pleurodesis with or without video-assisted thoracoscopic surgery (VATS).

Received June 7, 2011; Revised August 7, 2011; Accepted September 1, 2011

Abbreviations: CT, computed tomography; CTP, Child-Turcotte-Pugh; HBV, hepatitis B virus; HCV, hepatitis C virus; PCD, percutaneous drainage; PCR, polymerase chain reaction; SD, standard deviation; VATS, video-assisted thoracoscopic surgery

Corresponding author: Hong Joo Kim

Department of Internal Medicine, Kangbuk Samsung Hospital, Sungkyunkwan University School of Medicine, 78 Saemunan-gil, Jongno-gu,

Seoul 110-746, Korea

Tel. +82-2-2001-2060, Fax. +82-2-2001-2049, E-mail; hongjoo3.kim@samsung.com 


\section{PATIENTS AND METHODS}

\section{Patients}

Eleven consecutive patients with refractory hepatic hydrothorax and decompensated liver cirrhosis who underwent chemical pleurodesis with or without VATS in our institution between July 2007 and February 2011 were included. The Child-Turcotte-Pugh (CTP) class and etiology of cirrhosis was documented in all patients. All 11 patients had failed medical treatment because diuretics and other modes of therapy had not led to symptomatic improvement or caused electrolytes disturbances or impairment in renal function. Average diuretic dosages in the study population were spironolactone $200 \mathrm{mg} /$ day and furosemide $80 \mathrm{mg} /$ day. Of 11 patients, $10(90.9 \%)$ had coexisting ascites and the amount of ascites examined by abdominal ultrasonography were small in 9 patients and moderate in 1 patient, respectively. The diuretic treatment applied to these patients for the management of symptomatic hydrothorax was sufficient for the control of ascites. A medical history, physical examination, laboratory findings, and radiologic imagings including chest $\mathrm{X}$-ray, and computed tomographic (CT) scans of the chest and abdomen were thoroughly reviewed. Echocardiography was performed to measure left ventricular function in all 11 patients. Abdominal ultrasound or CT scans were performed in all 11 patients to examine the liver for size and structure and to determine the presence of ascites. Simultaneously with abdominal ultrasound, a Doppler study for patency of, and flow in, the hepatic and portal venous systems was also performed. Prior to the chemical pleurodesis with or without VATS, a diagnostic thoracentesis (approximately 40-50 mL of pleural fluid) was performed in all 11 patients for confirmation of diagnosis and to exclude alternative diagnoses. Diagnostic tests of pleural fluid to be ordered included cell count, Gram stain and culture of the pleural fluid in blood culture bottles and fluid protein, albumin, lactative dehydrogenase and bilirubin. Other tests in pleural fluid that would be appropriate depending on the clinical circumstance include triglyceride, pleural $\mathrm{pH}$, adenosine deaminase, and polymerase chain reaction (PCR) for mycobacterium, amylase, and cytology to exclude chylothorax, empyema, tuberculosis, pancreatitis and malignancy, respectively. This study was conducted in accordance with the principles of the Declaration of Helsinki. Our study protocol obtained approval of the Ethics Committee of Kangbuk Samsung
Hospital.

\section{VATS and chemical pleurodesis}

VATS was performed in two patients with the intent to provide chemical pleurodesis. The remaining 9 patients underwent only chemical peurodesis by tube thoracostomy. The agents used in chemical peurodesis were talc in 3 patients $(27.3 \%)$, taurolidine in 2 patients $(18.2 \%)$ and viscum album in 6 patients $(54.25 \%)$. The processes of chemical pelurodesis were performed as previously defined. ${ }^{5}$ VATS operative procedure was as follows. Patients received general anesthesia. The rigid pleural effusion was drained using by a $5-\mathrm{mm}$ rigid thoracoscopy. It was sent for body fluid chemistry, cytology and culture. If the fenestrations of hemidiaphragm were noticed during the thoracoscopic observation, they were closed using thoracoscopic technique with suture. The insufflated slcerosing agents used in VATS were talc $(20 \mathrm{~g})+$ bleomycin $(30 \mathrm{mg})$ in one patient and taurolidine $(10 \mathrm{~g})+$ bleomycin $(30 \mathrm{mg})$ in another patient.

\section{Definitions}

Successful pelurodesis was defined by a patient who had no longer dyspnea symptoms and had a chest roentgenogram that did not show pleural effusion at 1 month after the termination of VATS with chemical pleurodesis or chemical pleurodesis only. The definition for refractory hepatic hydrothorax has not been properly established. We adopted the definition of refractory hepatic hydrothorax as a symptomatic hepatic hydrothorax which was refractory to conventional treatments for hepatic hydrothorax, such as salt restriction, maximum tolerable dosage of diuretics, repeated thoracentesis and pleural drainage. Procedure related morbidity and mortality were defined as the occurrences of any complication and/or death within 1 month relevant to the adoption of chemical pleurodesis with or without VATS for the management of refractory hepatic hydrothorax in our enrolled patients.

\section{Statistical methods}

Mann-Whitney $U$-test for continuous variables and Fisher's exact test for categorical variables were performed. The comparison of the cumulative survival rate between success and non-success group was performed using a log-rank test with Kaplan-Meier analysis. Data were analyzed using 
PASW software package (version 18.0; SPSS, Inc., Chicago, IL, USA). $P$-values less than 0.05 were considered significant.

\section{RESULTS}

A total of 11 patients with refractory hepatic hydrothorax were included. Median (range) age of the patients was 63 (38-84) years and $6(54.5 \%)$ patients were male. The etiologies of liver cirrhosis were HBV ( $n=4,36.2 \%)$, HCV $(n=4,36.4 \%)$, alcoholic $(n=1,9.1 \%)$ and cryptogenic $(n=2$, $18.2 \%)$. Nine $(81.8 \%)$ and 2 patient were CTP class $\mathrm{C}$ and $\mathrm{B}$, respectively. All the patients have right sided pleural effusion refractory to medical therapy. The median (range) sessions of chemical pleurodesis were 3 (2-10) times. Nine

Table 1. Baseline characteristics of the subjects

\begin{tabular}{|c|c|}
\hline Characteristics & Values \\
\hline Number of patients & 11 \\
\hline Median age (range, years) & $63(38-84)$ \\
\hline Male gender $(\%)$ & $6(54.5)$ \\
\hline \multicolumn{2}{|l|}{ Causes of liver cirrhosis (\%) } \\
\hline Alcohol & $1(9.1)$ \\
\hline $\mathrm{HBV}$ & $4(36.4)$ \\
\hline $\mathrm{HCV}$ & $4(36.4)$ \\
\hline Cryptogenic & $2(18.2)$ \\
\hline \multicolumn{2}{|l|}{ Site of pleural effusion (\%) } \\
\hline Right & $11(100.0)$ \\
\hline Left & $0(0)$ \\
\hline \multicolumn{2}{|l|}{ Sclerosing agents for pleurodesis (\%) } \\
\hline Talc & $3(27.3)$ \\
\hline Taurolidine & $2(18.2)$ \\
\hline Viscum album & $6(54.5)$ \\
\hline \multicolumn{2}{|l|}{ Treatment method (\%) } \\
\hline Chemical pleurodesis only & $9(81.8)$ \\
\hline Chemical pleurodesis+VATS & $2(18.2)$ \\
\hline Median sessions of pleurodesis (range) & $3(2-10)$ \\
\hline \multicolumn{2}{|l|}{ Child-Turcotte-Pugh class (\%) } \\
\hline $\mathrm{B}$ & $2(18.2)$ \\
\hline $\mathrm{C}$ & $9(81.8)$ \\
\hline Median MELD score (range) & $16(9-21)$ \\
\hline \multicolumn{2}{|l|}{ Success of treatment ${ }^{*}$} \\
\hline Yes & $8(72.7)$ \\
\hline No & $3(27.3)$ \\
\hline Median follow-up periods (range, weeks) & $16(2-52)$ \\
\hline
\end{tabular}

* Success of treatment was defined by a patient who had no longer dyspnea symptoms and had a chest roentgenogram that did not show pleural effusion at 1 month after the termination of VATS with chemical pleurodesis or chemical pleurodesis only.

$\mathrm{SD}$, standard deviation; HBV, hepatitis B virus; HCV, hepatitis $\mathrm{C}$ virus; VATS, video- assisted thoracoscopic surgery; MELD, model for end stage liver disease. patients underwent only chemical pleurodesis via chest tube and two patients underwent chemical pleurodesis with VATS (Table 1). During the chemical pleurodesis with or without VATS, tolerable medical treatments such as low salt diet, diuretics and chest tube drainage were maintained. Diaphragmatic defects were not observed in the patients during the VATS procedure.

Successful pleurosdesis was achieved in 8 of 11 patients (72.7\%, Table 1). Representative radiologic findings of chest X-ray and CT were shown in Figure 1. By Kaplan-Meier analysis with log rank comparison, the overall survival was significantly longer in the success group than the non-success group $(P<0.01)$. Five $(62.5 \%)$ of the patients in the success group remained asymptomatic and hydrothorax free at a median follow-up of 16 (2-52) weeks after the procedure. However, three patients experienced symptomatic and delayed recurrence of hydrothorax 16, 30, and 32 weeks after the initial procedure. Complications occurred were low grade fever/leukocytosis $(\mathrm{n}=11,100.0 \%)$, pneumonia $(\mathrm{n}=1$, $9.1 \%)$, pneumothorax $(n=4,36.4 \%)$, azotemia/acute renal failure $(n=6,54.6 \%)$ and hepatic encephalopathy $(n=4$, $36.4 \%$ ). Chest pain and percutaneous drainage (PCD) site pain and chest pain occurred in all the 11 patients during the chemical pelurodesis. Five patients $(45.5 \%)$ were suspected to have procedure-related mortality due to the occurrence of acute renal failure (Table 2).

\section{DISCUSSION}

This study was as retrospective observational results in the patients with refractory hydrothorax and cirrhosis. The current study adds a report of 11 patients to the previously published series of chemical pleurodesis ${ }^{6-8}$ that examined the role of chemical pleurodesis with or without VATS for the management of refractory hepatic hydrothorax. The initial success of treatment was achieved in 8 of 11 patients $(72.7 \%)$ which was comparable to the treatment result of previously published case series. ${ }^{8}$ Notably, the cumulative survival rate was significantly higher in patients who achieved the initial success of treatment than patients without the initial success of treatment. The patients with initial treatment failure naturally underwent lesser sessions of chemical pleurodesis compared to the patients with successful treatment (albeit statistically insignificant) because the condition of a patient deteriorated, further session of 

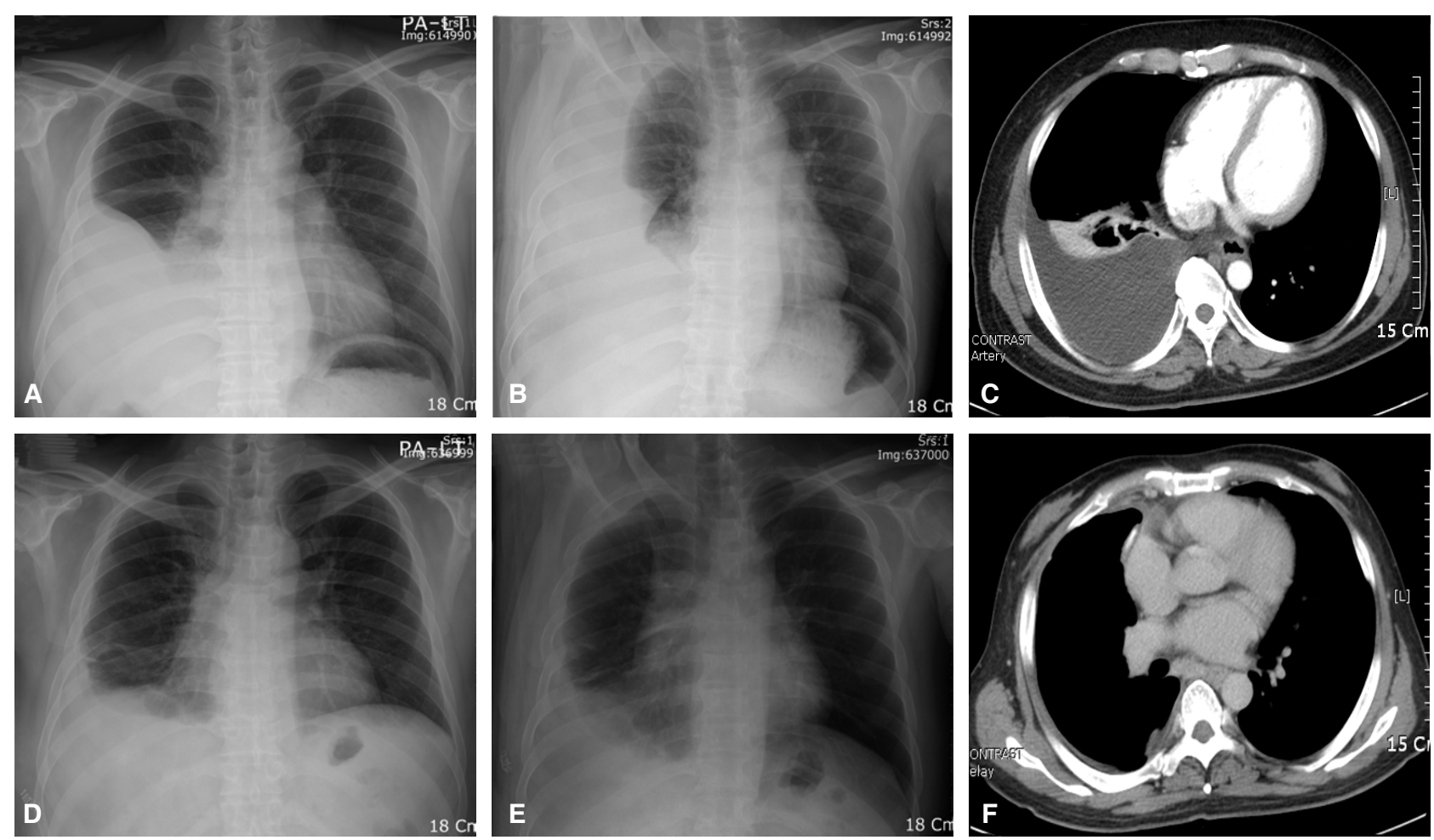

Figure 1. Changes in the radiologic findings of the same patient prior to (A-C) and following (D-F) chemical pleurodesis. Prior to chemical pleurodesis, the chest PA (A), chest right decubitus (B), and chest CT scan (C) revealed a large amount of right pleural effusion. Four sessions of chemical pleuro-desis with talc were performed successfully, and the follow-up chest PA (D), chest right decubitus (E), and chest $\mathrm{CT}$ scan $(\mathrm{F})$ performed 1 month after the last chemical pleurodesis revealed pleural thickening, but there was no fluid shifting in the right chest.

chemical pleurodesis could not be performed.

Ablation of the space between the parietal and visceral pleura with a sclerosing agent injected by tube thoracostomy has been used to treat hepatic hydrothorax. ${ }^{3}$ The procedure is generally unsuccessful, probably because fluid is formed too rapidly to allow the visceral and parietal pleural surfaces to approximate and adhere. ${ }^{6}$ Often, incomplete adhesions form between the parietal and visceral pleura, resulting in the formation of loculated pleural effusions. Thoracentesis does not evacuate all the fluid, because all locules cannot be aspirated. In addition, several complications may be associated with placement of a chest tube, including subcutaneous emphysema; lung, spleen, liver, and stomach laceration; unilateral pulmonary edema from rapid removal of fluid; and placement of the tube into the abdominal cavity. In the current study, complications associated with placement of a chest tube occurred in all enrolled patients, and most devastating complications were severe fluid and electrolytes imbalance and protein depletion leading the azotemia/acute renal failure. Five patients $(45.5 \%)$ were suspected to have procedure-related mortality due to the occurrence of these devastating complications (Table 2). Milder complications such as fever/leucocytosis occurred in all enrolled patients, and a significant proportion of patients with refractory hepatic hydrothorax who had treated with chemical pleurodesis only via a chest tube and chemical pleurodesis+VATS experienced more severe complications such as pneumonia $(\mathrm{n}=1,9.1 \%)$, pneumothorax $(\mathrm{n}=4,36.4 \%)$, azotemia/acute renal failure $(\mathrm{n}=6,54.6 \%)$ and hepatic encephalopathy $(\mathrm{n}=4$, $36.4 \%$, Table 2). Morbidity including PCD site pain and chest pain during chemical pleurodesis occurred in all the patients. Because of low success rates and procedurerelated complications, chest tube drainage of the pleural space for the routine treatment of hepatic hydrothorax is not recommended. However, the patients with advanced liver cirrhosis presenting with a unilateral pleural effusion, most commonly in the right side, usually present with symptoms related to shortness of breath, cough, hypoxemia and/or chest discomfort. Unlike the ascites, relief of symptoms and prevention of pulmonary complications and infections are critical for the patients with refractory hepatic hydrothorax who are potential candidates for liver transplantation. 
Table 2. Treatment outcomes of chemical pleurodesis with or without VATS in patients with hepatic hydrothorax

\begin{tabular}{|c|c|c|c|c|c|c|c|c|}
\hline No. & $\begin{array}{l}\text { Age/ } \\
\text { gender }\end{array}$ & Treatment & $\begin{array}{l}\text { Success } \\
\text { (yes/no) }\end{array}$ & $\begin{array}{l}\text { CTP } \\
\text { class }\end{array}$ & $\begin{array}{l}\text { Recurrence } \\
\text { (yes/no) }\end{array}$ & $\begin{array}{c}\text { Deceased } \\
\text { (yes/no) }\end{array}$ & $\begin{array}{l}\text { Survival } \\
\text { (days) }\end{array}$ & Complications \\
\hline 1 & $\begin{array}{c}63 / \\
\text { female }\end{array}$ & Chemical pleurodesis & No & $\mathrm{C}$ & Yes & Yes & 22 & $\begin{array}{l}\text { Fever/leucocytosis } \\
\text { Pneumothorax } \\
\text { Acute renal failure } \\
\text { Hepatic encephalopathy } \\
\text { Liver failure }\end{array}$ \\
\hline 2 & $\begin{array}{l}42 / \\
\text { male }\end{array}$ & $\begin{array}{c}\text { Chemical } \\
\text { pleurodesis+VATS }\end{array}$ & Yes & $\mathrm{C}$ & Yes & Yes & 577 & $\begin{array}{l}\text { Fever/leucocytosis } \\
\text { Pneumothorax } \\
\text { Acute renal failure } \\
\text { Liver failure }\end{array}$ \\
\hline 3 & $\begin{array}{c}71 / \\
\text { female }\end{array}$ & Chemical pleurodesis & No & $\mathrm{C}$ & Yes & Yes & 13 & $\begin{array}{l}\text { Fever/leucocytosis } \\
\text { Acute renal failure } \\
\text { Hepatic encephalopathy } \\
\text { Liver failure }\end{array}$ \\
\hline 4 & $\begin{array}{c}63 / \\
\text { male }\end{array}$ & Chemical pleurodesis & Yes & $\mathrm{C}$ & No & Yes & 33 & $\begin{array}{l}\text { Fever/leucocytosis } \\
\text { Acute renal failure } \\
\text { Liver failure }\end{array}$ \\
\hline 5 & $\begin{array}{l}57 / \\
\text { male }\end{array}$ & Chemical pleurodesis & Yes & B & No & Yes & 110 & $\begin{array}{l}\text { Fever/leucocytosis } \\
\text { Liver failure }\end{array}$ \\
\hline 6 & $\begin{array}{c}63 / \\
\text { female }\end{array}$ & $\begin{array}{c}\text { Chemical } \\
\text { pleurodesis+VATS }\end{array}$ & Yes & $\mathrm{C}$ & No & Yes & 98 & $\begin{array}{l}\text { Fever/leucocytosis } \\
\text { Pneumonia } \\
\text { GI bleeding }\end{array}$ \\
\hline 7 & $\begin{array}{c}51 / \\
\text { male }\end{array}$ & Chemical pleurodesis & Yes & $\mathrm{C}$ & Yes & Yes & 153 & $\begin{array}{l}\text { Fever/leucocytosis } \\
\text { Liver failure }\end{array}$ \\
\hline 8 & $\begin{array}{c}73 / \\
\text { female }\end{array}$ & Chemical pleurodesis & Yes & $\mathrm{C}$ & Yes & No & 212 & $\begin{array}{l}\text { Fever/leucocytosis } \\
\text { Pneumothorax } \\
\text { Acute renal failure } \\
\text { Hepatic encephalopathy }\end{array}$ \\
\hline 9 & $\begin{array}{c}70 / \\
\text { male }\end{array}$ & Chemical pleurodesis & Yes & B & No & No & 363 & Fever/leucocytosis \\
\hline 10 & $\begin{array}{c}38 / \\
\text { male }\end{array}$ & Chemical pleurodesis & Yes & $\mathrm{C}$ & No & No & 124 & $\begin{array}{l}\text { Fever/leucocytosis } \\
\text { Pneumothorax }\end{array}$ \\
\hline 11 & $\begin{array}{c}84 / \\
\text { female }\end{array}$ & Chemical pleurodesis & No & $\mathrm{C}$ & Yes & Yes & 20 & $\begin{array}{l}\text { Fever/leucocytosis } \\
\text { Acute renal failure } \\
\text { Hepatic encephalopathy } \\
\text { Liver failure }\end{array}$ \\
\hline
\end{tabular}

* Success of treatment was defined by a patient who had no longer dyspnea symptoms and had a chest roentgenogram that did not show pleural effusion at 1 month after the termination of VATS with chemical pleurodesis or chemical pleurodesis only. VATS, video-assisted thoracoscopic surgery; CTP, Child-Turcotte-Pugh.

Conventional treatment modalities for hepatic hydrothorax such as sodium restriction and diuretics, and intermittent thoracentesis cannot achieve the goals of treatment in many patients. Increasing the doses of diuretics to achieve the negative sodium balance may increase in the serum creatinine level, which indicates a decrease in the glomerular filtration rate. ${ }^{9}$ Moreover, increasing the doses of diuretics may precipitate hepatic encephalopathy. Although, thoracentesis for hepatic hydrothorax in clinical practice is both useful and safe, thoracentesis dependence may be associated with deteriorating clinical status and impaired quality of life. Actually, when thoracentesis is required every 2-3 weeks, alternative strategies were needed to be considered.

Transjugular intrahepatic portosystemic shunt (TIPS) 
were reported to have encouraging results in patients of hepatic hydrothorax with or without ascites. ${ }^{10-12}$ However, most of patients with TIPS for the treatment of hepatic hydrothorax developed hepatic encephalopathy and had the deterioration of liver function and subsequently died within 6 weeks of shunt placement. ${ }^{12}$ Another study also evaluated the clinical efficacy of TIPS in patients with hepatic hydrothorax and this study reported poor prognosis in patients with hepatic hydrothorax who underwent TIPS. ${ }^{13}$ In our institution, TIPS was not available and we did not consider this treatment modality for our enrolled patients with refractory hepatic hydrothorax. Hence, we could not compare the treatment results between chemical pleurodesis with or without VATS and TIPS in patients with refractory hepatic hydrothorax.

There are a few reports of successful primary repair of diaphragmatic defects. ${ }^{8,14}$ Evaluation for defects in the diaphragm formerly required a thoracotomy, which carries substantial risks. Recently, VATS was used to identify diaphragmatic defects in patients with refractory hepatic hydrothorax, and biologic glue or sutures were used to close the defects. ${ }^{15}$ However, VATS also required a general anesthesia, which carries substantial risks for the patients with advanced liver cirrhosis. Additionally, in contrast to the series by Mouroux et al, ${ }^{15}$ we did not identify any visible diaphragmatic defects in two patients who underwent chemical pelurodesis combined with VATS.

In a real clinical situation, where advanced liver cirrhosis patients with refractory hepatic hydrothorax who need symptomatic relief and the control of pulmonary complications are in the care of a physician who has a few available treatment modalities, chemical pleurodesis by tube thoracostomy may be a considerable treatment option for these intractable patients.

In the current study, success of treatment was identified as a significant prognostic indicator for patients with advanced liver cirrhosis and refractory hepatic hydrothorax. Previous study by Ferrante et al $^{8}$ also adopted the concept of success of treatment defined as control of symptomatic hydrothorax in the first 30 days after the VATS with talc pleurodesis. However, they did not figure out any prognostic significance of this concept "success of treatment". However, in the current study, the patient who achieved the success of treatment showed significantly better outcomes than the patients who did not achieve the success of treatment.
The current study has limitations to consider. First, the number of enrolled patients with refractory hepatic hydrothorax is too small to draw any statistical significance. Due to the rare frequency of hepatic hydrothorax, previously reported case series ${ }^{6-8}$ rarely included more than 20 patients with hepatic hydrothorax. Second, we could enroll only 2 cases with chemical pleurodesis with VATS due to the practical and psychological burdens of general anesthesia in patients with decompensated liver diseases. Hence, we could not evaluate the clinical efficacy of chemical pleurodesis with VATS to reduce the performed sessions of pleurodesis compared to the procedure without VATS.

In summary, this series suggests that refractory hepatic hydrothorax can be controlled with multiple sessions of chemical pleurodesis via chest tube with or without VATS in as many as $72.7 \%$ of patients. Additionally, the patients who achieved the success of treatment defined as symptoms free and no pleural effusion at 1 month after the termination of chemical pleurodesis and/or VATS, showed significantly better outcomes than those who did not achieve the success of treatment. However, due to a significantly high occurrence rate of procedure-related morbidity and mortality hindered the routine application of this procedure for patients with this debilitating complication of end stage liver disease. Further options of management, such as TIPS or chemical pleurodesis combined with nasal continuous positive airway pressure (CPAP) ${ }^{16}$ may be required for effective treatment for these patients. However, warrant future validation is needed.

\section{REFERENCES}

1. Morrow CS, Kantor M, Armen RN. Hepatic hydrothorax. Ann Intern Med 1958;49:193-203.

2. Strauss RM, Boyer TD. Hepatic hydrothorax. Semin Liver Dis 1997; 17:227-232.

3. Alberts WM, Salem AJ, Solomon DA, Boyce G. Hepatic hydrothorax. Cause and management. Arch Intern Med 1991;151:2383-2388.

4. Xiol X, Guardiola J. Hepatic hydrothorax. Curr Opin Pulm Med 1998;4:239-242.

5. Massard G, Thomas P, Wihlm JM. Minimally invasive management for first and recurrent pneumothorax. Ann Thorac Surg 1998;66: 592-599.

6. Ikard RW, Sawyers JL. Persistent hepatic hydrothorax after peritoneojugular shunt. Arch Surg 1980;115:1125-1127.

7. Runyon BA, Greenblatt M, Ming RH. Hepatic hydrothorax is a relative contraindication to chest tube insertion. Am J Gastroenterol 1986;81:566-567.

8. Ferrante D, Arguedas MR, Cerfolio RJ, Collins BG, van Leeuwen DJ. Video-assisted thoracoscopic surgery with talc pleurodesis in 
the management of symptomatic hepatic hydrothorax. Am J Gastroenterol 2002;97:3172-3175.

9. Arroyo V, Ginès P, Gerbes AL, Dudley FJ, Gentilini P, Laffi G, et al. Definition and diagnostic criteria of refractory ascites and hepatorenal syndrome in cirrhosis. International Ascites Club. Hepatology 1996;23:164-176.

10. Strauss RM, Martin LG, Kaufman SL, Boyer TD. Transjugular intrahepatic portal systemic shunt for the management of symptomatic cirrhotic hydrothorax. Am J Gastroenterol 1994;89:1520-1522.

11. Andrade RJ, Martin-Palanca A, Fraile JM, Alcantara R, Carmona C, Medina MC, et al. Transjugular intrahepatic portosystemic shunt for the management of hepatic hydrothorax in the absence of ascites. J Clin Gastroenterol 1996;22:305-307.

12. Gordon FD, Anastopoulos HT, Crenshaw W, Gilchrist B, McEniff N, Falchuk KR, et al. The successful treatment of symptomatic, refractory hepatic hydrothorax with transjugular intrahepatic portosystemic shunt. Hepatology 1997;25:1366-1369.

13. Chalasani N, Martin LG, Strauss RM, Boyer TD. Transjugular intrahepatic portosystemic shunt (Trends Pharmacal Sci) for refractory hepatic hydrothorax: good for the lungs, not so good for the liver [Abstract]. Hepatology 1997;26:286A.

14. Rubinstein D, McInnes IE, Dudley FJ. Hepatic hydrothorax in the absence of clinical ascites: diagnosis and management. Gastroenterology 1985;88:188-191.

15. Mouroux J, Perrin C, Venissac N, Blaive B, Richelme H. Management of pleural effusion of cirrhotic origin. Chest 1996; 109:1093-1096.

16. Saito R, Rai T, Saito H, Abe K, Takahashi A, Takiguchi J, et al. Two cases of intractable hepatic hydrothorax successfully treated with nasal CPAP. Nihon Shokakibyo Gakkai Zasshi 2006;103: 1146-1151. 